\title{
Prediction of survival prognosis after surgery in patients with symptomatic metastatic spinal cord compression from non-small cell lung cancer
}

\author{
Mingxing Lei ${ }^{1}$, Yaosheng Liu ${ }^{1 *}$, Chuanghao Tang², Shaoxing Yang ${ }^{2}$, Shubin Liu ${ }^{1 *}$ and Shiguo Zhou ${ }^{3}$
}

\begin{abstract}
Background: The aim of this study was to develop a scoring system for prediction of survival prognosis after surgery in patients with symptomatic metastatic spinal cord compression (MSCC) from non-small cell lung cancer (NSCLC).

Methods: We retrospectively analyzed nine preoperative characteristics for survival in a series of 64 patients with NSCLC who were operated with posterior decompression and spine stabilization for MSCC. Characteristics significantly associated with survival on multivariate analysis were included in the scoring system. The scoring point for each significant characteristic was derived from the hazard ratios on Cox proportional hazards model. The total score for each patient was obtained by adding the scoring points of all significant characteristics.

Results: Eastern Cooperative Oncology Group (ECOG) performance status, number of involved vertebrae, visceral metastases, and time developing motor deficits had significant impact on survival on multivariate analysis and were included in the scoring system. According to the prognostic scores, which ranged from 4 to 10 points, three prognostic groups were designed: $4-5$ points $(n=22), 6-7$ points $(n=23)$, and $8-10$ points $(n=19)$. The corresponding 6-month survival rates were 95,47 and $11 \%$, respectively $(P<0.0001)$. In addition, the functional outcome was worse in the group of patients with 8-10 points compared with other two prognostic groups.

Conclusions: The new scoring system will enable physicians to identify patient with MSCC from NSCLC who may be a candidate for decompression and spine stabilization, more radical surgery, or supportive care alone. Patients with scores of 4-5, who have the most favorable survival prognosis and functional outcome, can be treated with more radical surgery in order to realize better local control of disease and prevent the occurrence of local disease. Patients with scores of 6-7 points should be surgical candidates, because survival prognosis and functional outcome are acceptable after surgery, while patients with scores of 8-10 points, who have the shortest survival time and poorest functional outcome after surgery, appear to be best treated with radiotherapy or best supportive care.
\end{abstract}

Keywords: Metastatic spinal cord compression, Non-small cell lung cancer, Surgery, Score, Survival, Prediction

\footnotetext{
*Correspondence: 632763246@qq.com; Isb9126@126.com

*Correspondence: 632763246@qq.com; Isb9126@126.com
'Department of Orthopedic Surgery, Affiliated Hospital of Academy of Military Medical Sciences, No. 8, Fengtaidongda Rd, Beijing 100071, People's Republic of China

Full list of author information is available at the end of the article
}

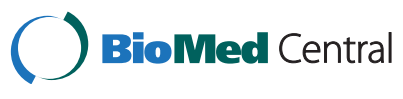

(c) 2015 Lei et al. Open Access This article is distributed under the terms of the Creative Commons Attribution 4.0 International License (http://creativecommons.org/licenses/by/4.0/), which permits unrestricted use, distribution, and reproduction in any medium, provided you give appropriate credit to the original author(s) and the source, provide a link to the Creative Commons license, and indicate if changes were made. The Creative Commons Public Domain Dedication waiver (http://creativecommons.org/publicdomain/zero/1.0/) applies to the data made available in this article, unless otherwise stated. 


\section{Background}

Metastatic spinal cord compression (MSCC) is a severe complication of cancer that occurs in $28 \%$ of patients with lung cancer and can become symptomatic, which involves intractable pain, disability, and incontinence [1-3], negatively impacting the patient's quality of remaining life. The optimal treatments for patients with MSCC are analgesics, corticosteroids, chemotherapy, radiotherapy and surgery, and most often these treatments are combined to give the maximum palliative effect with a minimum of operative morbidity and mortality $[1,4,5]$, positively improving the patient's quality of remaining life. Recently, an increasing number of studies supported the use of decompressive surgery as an effective treatment for MSCC due to the evolvement of surgical techniques [1, $2,6]$, while only a few studies specifically addressed surgical treatment of MSCC in lung cancer [7, 8], which was often associated with high morbidity and mortality [8]. A major problem in selection patients for surgery is to avoid operating on those who are likely to die very soon after surgery, so life expectancy is the most important selection criteria for surgery. While for patients with very short survival time radiotherapy or best supportive care alone are recommended, for patients with more favorable prognosis can be treated with decompressive surgery, or even more radical surgery such as excisional procedures $[4,9,10]$.

Some scoring systems were designed to estimate the survival time of each patient and select the optimal treatment strategy among supportive care, palliative radiotherapy, palliative surgery, and excisional surgery [9-15]. However, some old and commonly-used scoring systems have underestimated the life expectancy of lung cancer patients with spinal metastases because of the increased survival time for this patient group in recent years [16-19]. Notably, it is critical to regard patients with MSCC from a particular primary tumor type as a separate group of patients for individual treatment, because primary tumors vary with respect to their biological behavior. Therefore, our present study is designed to develop a new survival score particularly for patients with MSCC from non-small cell lung cancer (NSCLC) after surgery.

\section{Methods}

\section{Patients}

Sixty-four patients with NSCLC operated with decompression and spine stabilization for MSCC were retrospectively analyzed in the study at the Affiliated Hospital of Academy of Military Medical Sciences, Beijing, between May 2005 and May 2015. The diagnosis of bone metastasis in NSCLC patients was confirmed histologically, adequate diagnostic imaging including spinal CT or MRI, as well as bone scan.
Patients with an estimated survival less than 3 months or health too poor to undergo surgery were excluded. Of the total series of 64 patients, six patients were treated with radical resection of primary lung cancer, while others weren't. The data were collected from patients, their family members, treating surgeons, and patients' files. The Medical Research Ethics Board of the Affiliated Hospital of Academy of Military Medical Sciences approved this retrospective study and required neither patient approval nor informed consent for review of patients' images and medical records. The data were retrospective in nature and anonymized by the Medical Research Ethics Board.

Table 1 Univariate analysis of preoperative factors for postoperative survival in patients with MSCC from NSCLC

\begin{tabular}{|c|c|c|c|c|c|}
\hline \multirow[t]{2}{*}{ Factors } & \multirow[t]{2}{*}{ Patients (n) } & \multicolumn{2}{|l|}{ Survival } & \multirow{2}{*}{$\begin{array}{l}\text { MOS } \\
\text { (mo) }\end{array}$} & \multirow[t]{2}{*}{$P$} \\
\hline & & $6 \mathrm{mo}(\%)$ & $12 \mathrm{mo}(\%)$ & & \\
\hline \multicolumn{6}{|l|}{ Age } \\
\hline$\leq 57$ years & 34 & 61 & 27 & 7.1 & \multirow[t]{2}{*}{0.16} \\
\hline$\geq 58$ years & 30 & 42 & 18 & 4.8 & \\
\hline \multicolumn{6}{|l|}{ Gender } \\
\hline Female & 22 & 55 & 23 & 6.3 & \multirow[t]{2}{*}{0.90} \\
\hline Male & 42 & 52 & 24 & 6.2 & \\
\hline \multicolumn{6}{|c|}{ Preoperative ambulatory status } \\
\hline Ambulatory & 33 & 64 & 32 & 8.8 & \multirow[t]{2}{*}{0.003} \\
\hline Nonambulatory & 31 & 41 & 14 & 4.8 & \\
\hline \multicolumn{6}{|c|}{ Other bone metastases } \\
\hline No & 16 & 69 & 21 & 7.9 & \multirow[t]{2}{*}{0.58} \\
\hline Yes & 48 & 47 & 23 & 4.9 & \\
\hline \multicolumn{6}{|c|}{ ECOG performance status } \\
\hline $1-2$ & 43 & 66 & 29 & 8.8 & \multirow[t]{2}{*}{$<0.001$} \\
\hline $3-4$ & 21 & 26 & 5 & 4.5 & \\
\hline \multicolumn{6}{|c|}{ Number of involved vertebrae } \\
\hline $1-2$ & 36 & 67 & 35 & 7.9 & \multirow[t]{2}{*}{0.001} \\
\hline$\geq 3$ & 28 & 36 & 9 & 4.4 & \\
\hline \multicolumn{6}{|l|}{ Visceral metastases } \\
\hline No & 33 & 78 & 36 & 10.8 & \multirow[t]{2}{*}{0.002} \\
\hline Yes & 31 & 27 & 10 & 4.3 & \\
\hline \multicolumn{6}{|c|}{ Interval from cancer diagnosis to surgery } \\
\hline$\leq 80$ days & 32 & 59 & 24 & 7.1 & \multirow[t]{2}{*}{0.73} \\
\hline$>80$ days & 32 & 47 & 22 & 5.5 & \\
\hline \multicolumn{6}{|c|}{ Time developing motor deficits } \\
\hline$\leq 14$ days & 30 & 30 & 7 & 3.9 & \multirow[t]{2}{*}{$<0.001$} \\
\hline$>14$ days & 34 & 72 & 37 & 10.8 & \\
\hline
\end{tabular}

MSCC indicates metastatic spinal cord compression; NSCLC, non-small cell lung cancer; MOS, median overall survival; MO, months; ECOG, Eastern Cooperative Oncology Group 


\section{Survival analysis}

We retrospectively analyzed nine preoperative characteristics for survival, including age ( $\leq 57$ years vs. $\geq 58$ years; median age: 57 years), gender (female vs. male), preoperative ambulatory status (ambulatory vs. nonambulatory), other bone metastases (no vs. yes), Eastern Cooperative Oncology Group (ECOG) performance status (1-2 vs. 34 ), number of involved vertebrae (1-2 vs. $\geq 3$, conformed to previous studies), visceral metastases (no vs. yes), interval from cancer diagnosis to surgery ( $\leq 80$ days vs. $>80$ days; median time: 80 days), and the time developing motor deficits before surgery ( $\leq 14$ days vs. $>14$ days, conformed to previous studies).

The postoperative survival was defined as the time between the date of surgery and death or the latest followup. For the present study, we included all 64 patients with NSCLC who had decompressive surgery and spine stabilization due to spinal cord compression. None of the patients were excluded for any reason. 5 patients were still alive by the end of the study period, with a mean follow-up of 9.7 months in those patients. In patients who had surgery for more than one metastasis, all
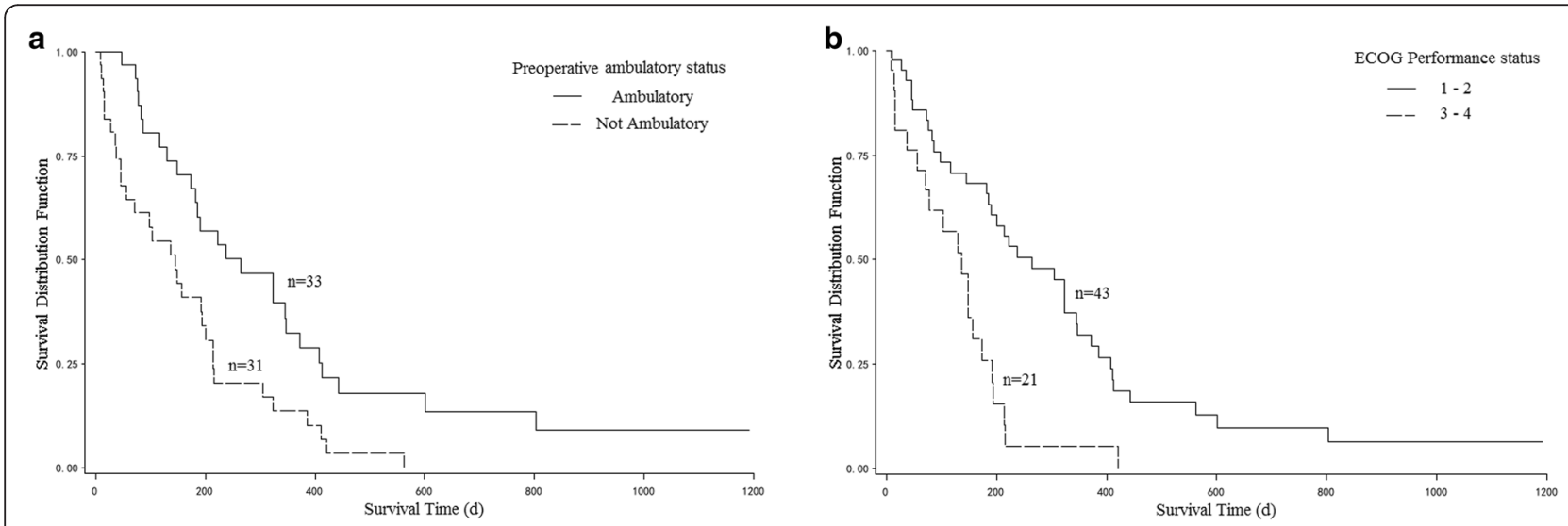

C

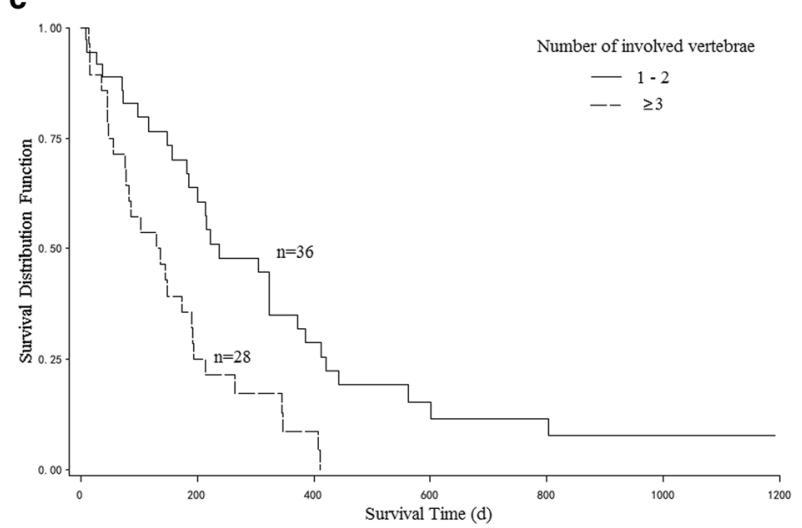

d
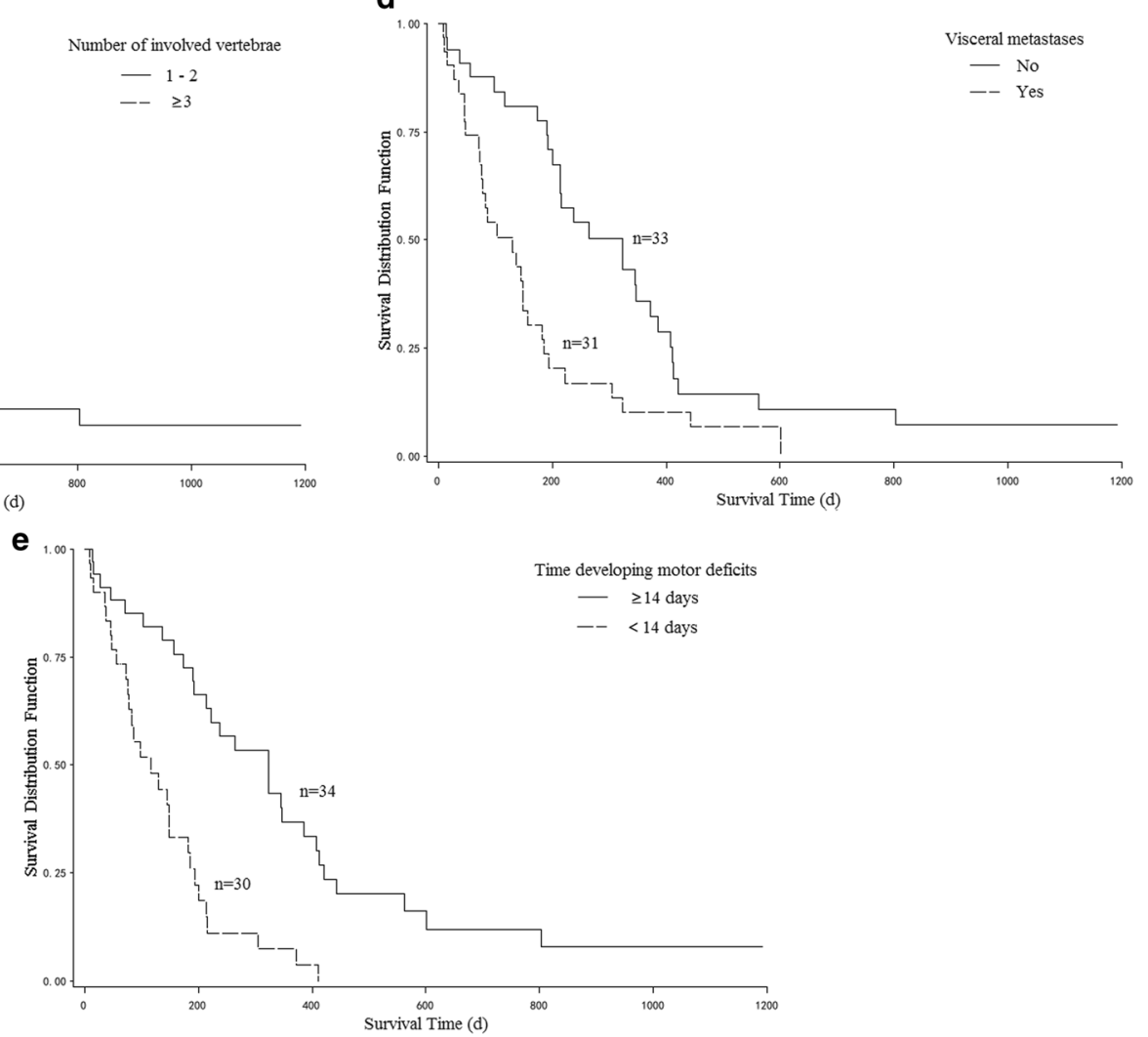

Fig. 1 Kaplan-Meier survival curves for preoperative factors: (a) Preoperative ambulatory status, (b) ECOG performance status, (c) Number of involved vertebrae, (d) Visceral metastases, and (e) Time developing motor deficits 
Table 2 The Cox proportional hazards model analysis of preoperative factors for postoperative survival in patients with MSCC from NSCLC

\begin{tabular}{|c|c|c|c|c|}
\hline \multirow[t]{2}{*}{ Factors } & \multicolumn{2}{|c|}{ Simple cox regression } & \multicolumn{2}{|c|}{ Multiple cox regression } \\
\hline & $\mathrm{HR}(95 \% \mathrm{Cl})$ & P & $\mathrm{HR}(95 \% \mathrm{Cl})$ & $P$ \\
\hline Preoperative ambulatory status & $2.24(1.30-3.86)$ & 0.004 & Excluded $^{\mathrm{a}}$ & \\
\hline ECOG performance status & $2.78(1.54-5.02)$ & $<0.001$ & $2.18(1.15-4.16)$ & 0.017 \\
\hline Number of involved vertebrae & $2.46(1.39-4.35)$ & 0.002 & $2.05(1.11-3.76)$ & 0.021 \\
\hline Visceral metastases & $2.29(1.33-3.94)$ & 0.003 & $2.00(1.10-3.62)$ & 0.022 \\
\hline Time developing motor deficits & $3.44(1.90-6.22)$ & $<0.001$ & $2.70(1.45-5.03)$ & 0.002 \\
\hline
\end{tabular}

MSCC indicates metastatic spinal cord compression; NSCLC, non-small cell lung cancer; ECOG, Eastern Cooperative Oncology Group; $H R$, hazard ratio; $C l$, confidence interval aSelection = stepwise, preoperative ambulatory status was excluded in the model

sites were included in the analysis. However, only the first surgical procedure was accounted for in the survival analysis.

\section{Surgery and functional evaluation}

The indication for surgery was neurological deficit due to spinal cord compression. All patients were operated with posterior decompression and stabilization in our department. Local radiotherapy, systemic chemotherapy, and targeted therapy with gefitinib were performed after the wound healed, about 3-4 weeks after the surgery. Postoperative functional outcome was analyzed according to the scoring system. Neurological function was graded based on Frankel et al. [20] preoperatively and 4 weeks postoperatively (Patients with Frankel D and $E$ have the ability to walk). Time developing motor deficits was defined as the time between deterioration of motor function to disability or surgery. Deterioration of motor function was defined as a change of at least one Frankel grade.

\section{Statistical analysis}

The univariate analysis of survival was performed using the Kaplan-Meier method and the log-rank test. The significant prognostic factors $(P<0.05)$ were additionally evaluated in a multivariate analysis performed with the Cox proportion hazards model (multiple Cox regression, selection $=$ stepwise). The prognostic factors that were significant in the multivariate analysis were included in the scoring system. The prognostic factors that were excluded by Cox proportion hazards model (multiple Cox regression, selection $=$ stepwise) were not included in the scoring system. The scoring point for each significant factors was derived from the hazard ratios on Cox proportional hazards model (simple Cox regression). The total prognostic score for each patient was determined by adding the scoring points of every significant factor. Neurological outcome in risk groups was compared with Chi-square test and Fisher exact test. A $P$ value of 0.05 or less was considered statistically significant. Statistical analysis was performed using SAS 9.2 software.

\section{Results}

Patient characteristics and survival

A total of 64 patients were included in the study, 34 \% (22/ $64)$ of patients were female, and $66 \%$ (42/64) were male. The overall median age was 57 years old. The median time interval from diagnosis to surgery was 80 days, and the median time developing motor deficits was 14 days.

For all patients, the overall median survival time was 6.3 months (95\% confidence interval, 4.5-7.4 months), 6-month and 12-month survival rates were 52.6 and $23 \%$, respectively. At the latest follow-up, 5 patients were still alive, with a mean follow-up of 9.7 months.

\section{Scoring system}

On the univariate analysis, survival was significantly associated with preoperative ambulatory status $(P=0.003)$, ECOG performance status $(P<0.001)$, number of involved vertebrae $(P=0.001)$, visceral metastases $(P=$ $0.002)$, and time developing motor deficits $(P<0.001$,

Table 3 Hazard ratio and corresponding scores of each significant factors in the scoring system

\begin{tabular}{llll}
\hline Factors & Patients $(n)$ & HR & Scoring points \\
\hline ECOG performance status & 43 & 1 & 1 \\
$1-2$ & 21 & 2.78 & 3 \\
$2-4$ & 36 & 1 & 1 \\
$\begin{array}{l}\text { Number of involved vertebrae } \\
1-2\end{array}$ & 28 & 2.46 & 2 \\
$\geq 3$ & 33 & & \\
Visceral metastases & & 1 & 1 \\
No & 31 & 2.29 & 2 \\
Yes & 30 & & \\
Time developing motor deficits & 3.44 & 3 \\
$<14$ days & 34 & 1 & 1 \\
$\geq 14$ days & 30
\end{tabular}

$H R$ indicates hazard ratio, ECOG Eastern Cooperative Oncology Group 


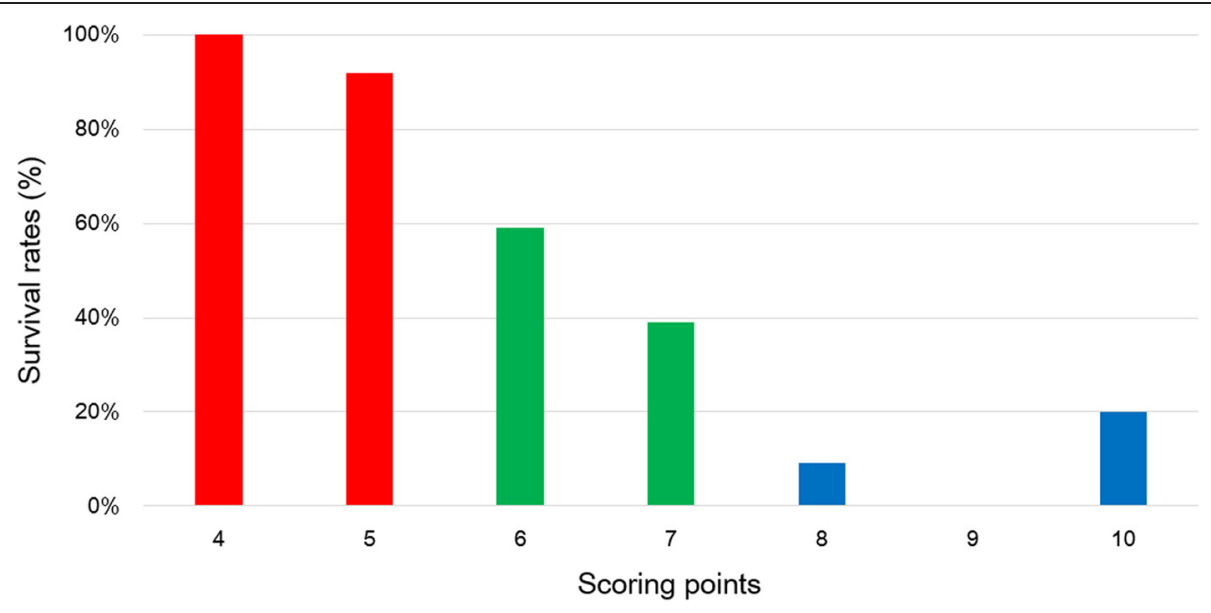

Fig. 2 The total scores and corresponding 6-month survival rates (\%)

Fig. 1, Table 1). On Cox proportional hazards model (multiple Cox regression, selection $=$ stepwise), four of above five factors, ECOG performance status $(P=0.017)$, number of involved vertebrae $(P=0.021)$, visceral metastases $(P=0.022)$, and time developing motor deficits $(P=$ 0.002 ), maintained significant impact on survival and were included in the scoring system (Table 2). The scoring points for each of the four significant factors obtained from the hazard ratios on Cox proportional hazards model (simple Cox regression) were seen in Table 3. The prognostic score for each patient was calculated by adding the scoring points of the four significant characteristics. The addition resulted in prognostic scores of 4, 5, 6, 7, 8, 9, 10 points. The 6-month survival rates of the prognostic scores were shown in Fig. 2. Taking into account the 6month survival rates of the prognostic scores, the following three survival groups were formed: $4-5$ points (group A, $n=22$ ), 6-7 points (group B, $n=23$ ), and 8-10

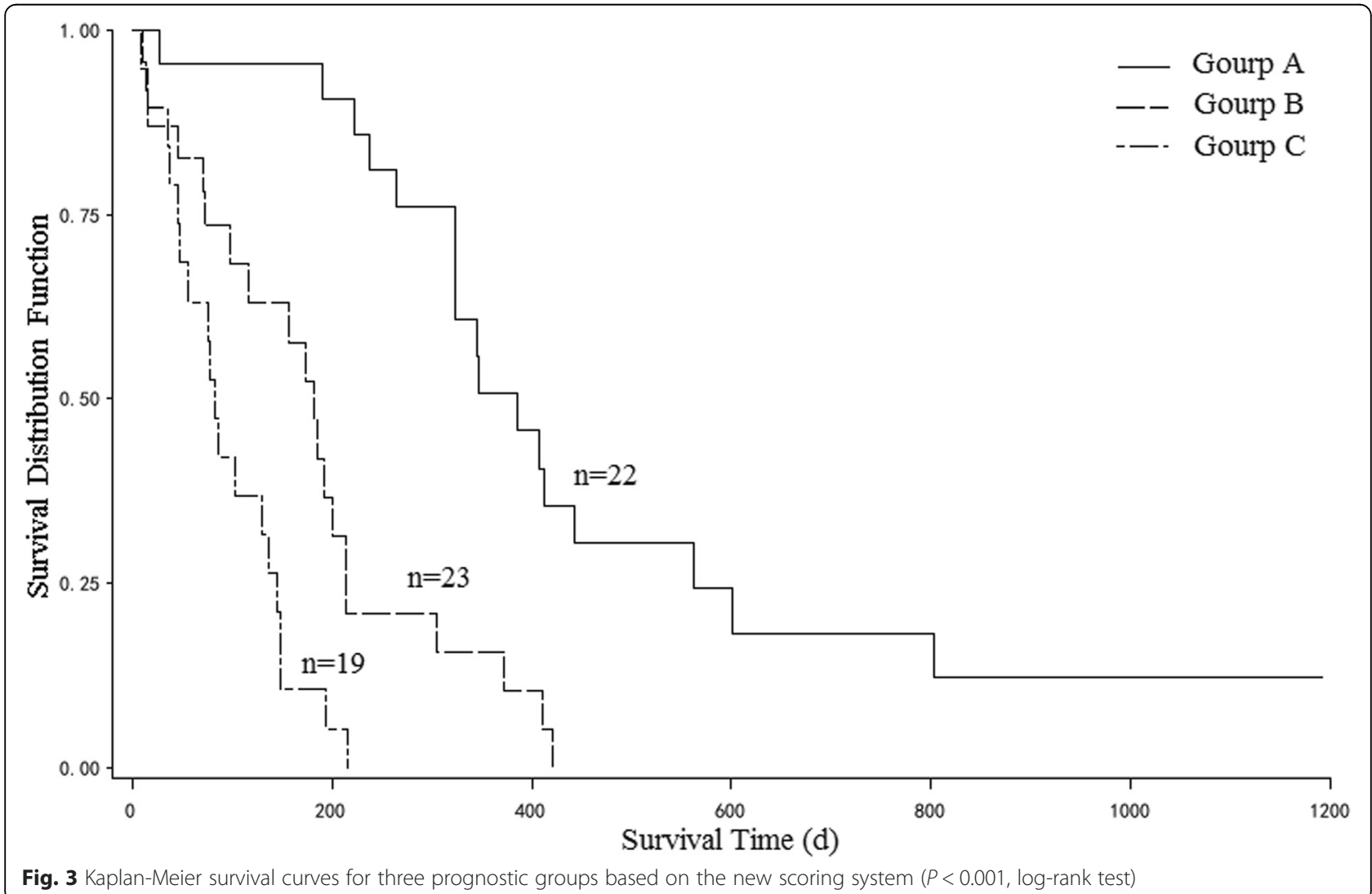


points (group $C, n=19$ ). The corresponding median survival times were 12.8 months (95\% confidence interval, 8.8-18.7 months), 6.4 months (95\% confidence interval, 3.8-7.4 months) and 2.7 months (95\% confidence interval, 1.5-4.5 months), respectively, and 6-month survival rates were 95,47 and $11 \%$, respectively $(P<0.001$, Fig. 3$)$.

\section{Functional outcome}

The functional outcome was worse in the group of patient with 8-10 points (group C) compared with the other two prognostic groups (Table 4). In detail, $86 \%$ $(19 / 22)$ patients were ambulatory 4 weeks after surgery in group A, $74 \%(17 / 23)$ patients in group B, and only $42 \%(8 / 19)$ patients in group C.

In the entire cohort of 64 patients, $68.8 \%$ (44 of 64) of the patients were able to walk 4 weeks after decompression, $51.6 \%(16 / 31)$ of nonambulatory patients before operation regained the ability to walk, and $84.8 \%(28 / 33)$ of ambulatory patients maintained their neurological status, whereas $15.2 \%(5 / 33)$ of ambulatory patients before surgery lost their ability to walk for disease progression. Six patients died within 4 weeks after surgery and none of them achieved ambulation.

\section{Discussion}

Individually treatment needs to be planned for each patient with MSCC to give the maximum palliative effect: reduction in pain, recovery of function, and improvement in the patient's quality of remaining life. Selection of the optimal treatment for the individual patient with MSCC should take into account patient's estimated survival time, as well as functional outcome after therapies. Only those who survive long enough, more than 3 months, can benefit from surgery [21, 22]. In contrast, patients with very short survival time and poor functional outcome appear to be best treated with radiotherapy or even best supportive care alone, which means less discomfort for these debilitated and enervated patient [4, 10]. Remarkably, it is also critical to regard patients with MSCC from a particular primary tumor type as a separate group of patients for optimal treatment, because primary tumors vary with respect to their biological behavior. Crnalic et al. [23] presented a score specifically for predicting survival of patients with prostate cancer after surgery for MSCC. However, who may benefit from surgery, and what kind of patients are appropriate for supportive care, remains nuclear in NSCLC patients with MSCC.

Several scoring systems have been proposed for predicting survival in patient with spinal metastasis on the basis of retrospective data from various primary tumors treated with surgery or radiotherapy alone. However, these scores comprised relatively small number of patient with lung cancer (Tokuhashi 6 [9], revised Tokuhashi 26 [10], Tomita 10 [11], Van der Linden 68 [12], Sioutos 45 [13], Bauer 6 [14], Bartels 28 [15], more details were seen in Table 5), making it difficult to draw conclusions on this specific tumor type.

Although the revised Tokuhashi was found to be useful to predict survival for patients with spinal metastases from breast cancer alone [4] or solid cancers [24, 25], which seems to be a suboptimal tool for the prediction of an individual prognosis in the group of patients with lung cancer (Hessler et al. [16]). In their study, 67 patients with spinal metastasis from lung cancer, all of them underwent surgical treatment. Hessler et al. [16] concluded that the Tokuhashi scoring system underestimated the life expectancy of lung cancer patients due to the increased survival time for this patient group. In 2013, Morgen et al. [17] also found a statistically significant increase in survival over the years for lung cancer patients with MSCC $(n=2321,499$ patients with lung cancer, 103 lung cancer patients received surgical treatment). For patients with lung cancer who underwent surgery for MSCC, survival increased from $9 \%$ in year 2005 up to $30 \%$ in year $2010(P=0.047)$. More recent studies have reported improvements among patients with advanced lung cancer because of the new treatment options $[18,19]$. Therefore, with the increasing survival time of patients with lung cancer during recent years, the Tokuhashi scoring system and other scores may no longer be suitable for patients with lung cancer.

Furthermore, these scores were designed for patients with spinal metastasis in general, not particularly for patients with motor impairment due to MSCC. Rades et al. [26] developed and validated a scoring system for survival

Table 4 Neurological recovery of the patients in 3 prognostic groups 4 weeks after surgery

\begin{tabular}{|c|c|c|c|c|c|}
\hline \multirow[t]{2}{*}{ Groups } & \multirow[t]{2}{*}{ Scores } & \multirow[t]{2}{*}{ Patients $(n)$} & \multicolumn{2}{|c|}{ Neurological status weeks postoperation } & \multirow[t]{2}{*}{$P$ values } \\
\hline & & & Ambulatory & Nonambulatory & \\
\hline A & $4-5$ & 22 & 19 & 3 & $P 1=0.502$ \\
\hline B & $6-7$ & 23 & 17 & 6 & $P 2=0.037$ \\
\hline C & $8-10$ & 19 & 8 & $11^{\mathrm{a}}$ & $P 3=0.003$ \\
\hline
\end{tabular}

P1 Group A compared with group B, Continuity Adjusted Chi-square test;

$P 2$ Group B compared with group $C$, Chi-square test;

$P 3$ Group C compared with group A, Chi-square test

${ }^{a} 2$ patients died within 4 weeks, none of both realized ambulatory status 
Table 5 Commonly-used and our scoring systems for patient with spinal metastases ${ }^{a}$

\begin{tabular}{|c|c|c|c|c|c|c|}
\hline Scoring systems & MOS (m) & Suggestions & No. of LC (Total) & Spinal metastasis & Treatments & Parameters \\
\hline \multicolumn{7}{|l|}{ Tokuhashi [9] } \\
\hline Group A & 3 & Palliative surgery & \multirow[t]{3}{*}{$6(64)$} & In general & \multirow[t]{3}{*}{ All surgery ${ }^{c}$} & \multirow{3}{*}{$\begin{array}{l}\text { PS; Extraspinal bone metastases; } \\
\text { Metastases in the vertebral body; } \\
\text { Metastases to major organs; } \\
\text { primary tumor site; Spinal } \\
\text { cord palsy }\end{array}$} \\
\hline Group B & 6 & - & & & & \\
\hline Group C & 22 & Excisional surgery & & & & \\
\hline \multicolumn{7}{|c|}{ Revised Tokuhashi [10] } \\
\hline Group A & 4.9 & Conservation therapy & \multirow[t]{3}{*}{$26(246)$} & In general & \multirow{3}{*}{$\begin{array}{l}164 \text { patients was } \\
\text { treated with surgery }\end{array}$} & \multirow{3}{*}{$\begin{array}{l}\text { PS; Extraspinal bone metastases; } \\
\text { Metastases in the vertebral body; } \\
\text { Metastases to major organs; } \\
\text { Primary tumor site; Spinal } \\
\text { cord palsy }\end{array}$} \\
\hline Group B & 9.5 & Palliative surgery & & & & \\
\hline Group C & 19 & Excisional surgery & & & & \\
\hline \multicolumn{7}{|l|}{ Tomita [11] } \\
\hline Group A & 6 & Supportive care & \multirow[t]{4}{*}{$10(67)$} & In general & \multirow{4}{*}{$\begin{array}{l}58 \text { patients was } \\
\text { treated with surgery }\end{array}$} & \multirow{4}{*}{$\begin{array}{l}\text { No. of extraspinal bone metastases; } \\
\text { Metastases to major internal organs; } \\
\text { Primary tumor site; Spinal cord palsy }\end{array}$} \\
\hline Group B & 15 & Palliative surgery & & & & \\
\hline Group C & 24 & Intralesional/marginal & & & & \\
\hline Group D & 50 & Excisional surgery & & & & \\
\hline \multicolumn{7}{|c|}{ Van der Linden [12] } \\
\hline Group A & 4.8 & Radiotherapy & \multirow[t]{3}{*}{$68(324)$} & No MSCC & \multirow[t]{3}{*}{ Radiotherapy alone } & \multirow{3}{*}{$\begin{array}{l}\text { KPS; Primary tumor; } \\
\text { Visceral metastases }\end{array}$} \\
\hline Group B & 13.1 & Radiotherapy & & & & \\
\hline Group C & 18.3 & Surgery & & & & \\
\hline \multicolumn{7}{|l|}{ Sioutos [13] } \\
\hline $3^{b}$ & 1.5 & No surgery & \multirow[t]{4}{*}{$45(109)$} & MSCC & \multirow[t]{4}{*}{ All surgery ${ }^{d}$} & \multirow{4}{*}{$\begin{array}{l}\text { Preoperative neurological status; } \\
\text { Anatomic site of primary } \\
\text { carcinoma; No. of vertebral } \\
\text { bodies involved }\end{array}$} \\
\hline $2^{\mathrm{b}}$ & 6.0 & No surgery & & & & \\
\hline $1^{\mathrm{b}}$ & 11.2 & Radical surgery & & & & \\
\hline $0^{\mathrm{b}}$ & 18.0 & Radical surgery & & & & \\
\hline \multicolumn{7}{|l|}{ Bauer [14] } \\
\hline Group A & - & No surgery & \multirow[t]{3}{*}{$6(88)$} & In general & \multirow[t]{3}{*}{ All surgery ${ }^{e}$} & \multirow{3}{*}{$\begin{array}{l}\text { Visceral metastases; No. of skeletal } \\
\text { metastases; Primary cancer type. }\end{array}$} \\
\hline Group B & - & Dorsal surgery & & & & \\
\hline Group C & - & Ventral-dorsal surgery & & & & \\
\hline \multicolumn{7}{|l|}{ Bartels [15] } \\
\hline Not reported & & & $28(219)$ & In general & Radiotherapy alone & $\begin{array}{l}\text { Sex; Location of the primary lesion; } \\
\text { Curative treatment of the primary } \\
\text { tumor; Location of the spinal } \\
\text { metastasis; KPS }\end{array}$ \\
\hline \multicolumn{7}{|l|}{ Ours } \\
\hline Group A & 12.8 & More radical surgery & \multirow[t]{3}{*}{$64(64)$} & MSCC & \multirow[t]{3}{*}{ All surgery ${ }^{e}$} & \multirow{3}{*}{$\begin{array}{l}\text { ECOG performance status; No. } \\
\text { of involved vertebrae; Visceral } \\
\text { metastases; Time developing } \\
\text { motor deficits. }\end{array}$} \\
\hline Group B & 6.4 & Depressive surgery & & & & \\
\hline Group C & 2.7 & Supportive care & & & & \\
\hline
\end{tabular}

MOS indicates mean overall survival; $L C$, lung cancer; $P S$, performance status; $K P S$, karnofsky performance status; $M S C C$, metastatic spinal cord compression, ECOG, Eastern Cooperative Oncology Group

${ }^{a}$ Functional outcome are not considered in all of their original studies

${ }^{\mathrm{b}}$ No. of negative prognostic factors

'Excisional or palliative procedure

${ }^{\mathrm{d}}$ Anterior or posterior approach

ePosterior approach

of patients ( $n=356$, all patients with lung cancer) with MSCC from NSCLC who had been treated with radiotherapy alone. Aside from the Rades score, the above mentioned scoring systems included relatively small number of patients with spinal metastasis from various primary tumors. In fact, participants in Rades score received radiotherapy alone, and the functional outcome was not considered either. Moreover, patients who had prior surgery to the involved parts of the spinal cord were excluded in their study. 
In our study, a score was developed based on the data derived from 64 patients with NSCLC who underwent decompressive surgery and spine stabilization for MSCC. The indication for surgery was neurological deficits. Functional outcome was also considered according to the scoring system. The patient's individual situation, therefore, is taken more into account in the present scoring system. Patients with scores of 4-5 survived more than 1 year in median time, and $86 \%$ patients were ambulatory 4 weeks after surgery. More radical surgery, such as widely excision of vertebra metastasis, can be considered in order to realize better local control of disease and prevent the occurrence of local disease in those patients. Patients with scores of $6-7$ points should be surgical candidates, because survival prognosis and functional outcome were favorable after surgery. Patients with scores of $8-10$ points, who survived 2.7 months in median time and had the worst functional outcome after surgery compared with other two prognostic groups, appeared to be best treated with radiotherapy or best supportive care alone. Functional outcome was acceptable in the entire cohort of 64 patients, $68.8 \%$ (44 of 64) patients were able to walk 4 weeks after decompression; $51.6 \%$ (16/31) of nonambulatory patients before operation regained the ability to walk. $74-84 \%$ patients were able to walk after surgery $[6,7,27]$ and $22-68 \%$ of nonambulatory patients became ambulatory again in other studies [7 28].

However, patients with asymptomatic MSCC were not included in our study, so this scoring system doesn't pertain to those patients. Besides, our score was based on retrospective data, and the statistical analysis didn't include a relatively larger number of patients, and data on systemic treatment following treatment was not available in most patients. Despite good predictive value in our scoring system, the score still warrants a prospective study to be confirmed.

\section{Conclusion}

We present a new score for predicting survival of patients with NSCLC operated with posterior decompression and spine stabilization for MSCC. Functional outcome after surgery was also considered in our study. The scoring system can help select the individual treatment for patients with MSCC from NSCLC. Patients with scores of $4-5$, who have the most favorable survival prognosis and functional outcome, can be treated with more radical surgery in order to realize better local control of disease and prevent the occurrence of local disease. $\mathrm{Pa}$ tients with scores of 6-7 points should be surgical candidates, because survival prognosis and functional outcome are acceptable after surgery, while patients with scores of 8-10 points, who have the shortest survival time and poorest functional outcome after surgery, appear to be best treated with radiotherapy or best supportive care. Still, a prospective study is needed.

\section{Abbreviations}

ECOG: Eastern Cooperative Oncology Group; MSCC: metastatic spinal cord compression; NSCLC: non-small cell lung cancer.

\section{Competing interests}

The authors declare that they have no competing interests.

\section{Authors' contributions}

$M L$ conceived of the study, and participated in its design and conception and drafted the manuscript. YL provided the administrative support, and participated in Collection and assembly of data. $\mathrm{CT}$ participated in design and conception. SY participated in Collection and assembly of data. SL drafted the manuscript. SZ participated in design and conception and performed the statistical analysis. All authors read and approved the final manuscript.

\section{Acknowledgements}

The work is supported by Application Study of Capital Clinical Characteristics of China (NO. Z131107002213052).

\section{Author details}

${ }^{1}$ Department of Orthopedic Surgery, Affiliated Hospital of Academy of Military Medical Sciences, No. 8, Fengtaidongda Rd, Beijing 100071, People's Republic of China. ${ }^{2}$ Department of Pulmonary Neoplasms Internal Medicine, Affiliated Hospital of Academy of Military Medical Sciences, No. 8, Fengtaidongda Rd, Beijing, China. ${ }^{3}$ Statistics Room, Capital Medical University affiliated Beijing Friendship Hospital, No. 95, Xuanwu District Yongan Rd, Beijing, China.

Received: 19 June 2015 Accepted: 27 October 2015

Published online: 05 November 2015

\section{References}

1. Prasad D, Schiff D. Malignant spinal cord compression. Lancet Oncol. 2005:6:15-24.

2. Hirabayashi H, Ebara S, Kinoshita T, Yuzawa Y, Nakamura I, Takahashi J, et al. Clinical outcome and survival after palliative surgery for spinal metastases: palliative surgery in spinal metastases. Cancer. 2003;97:476-84.

3. Silva GT, Bergmann A, Thuler LC. Incidence, associated factors, and survival in metastatic spinal cord compression secondary to lung cancer. Spine J. 2015;15:1263-9.

4. Ulmar B, Richter M, Cakir B, Muche R, Puhl W, Huch K. The Tokuhashi score: significant predictive value for the life expectancy of patients with breast cancer with spinal metastases. Spine. 2005:30:2222-6.

5. Wai EK, Finkelstein JA, Tangente RP, Holden L, Chow E, Ford M, et al. Quality of life in surgical treatment of metastatic spine disease. Spine. 2003;28:508-12.

6. Patchell RA, Tibbs PA, Regine WF, Payne R, Saris S, Kryscio RJ, et al. Direct decompressive surgical resection in the treatment of spinal cord compression caused by metastatic cancer: a randomised trial. Lancet. 2005;366:643-8.

7. Chen YJ, Chang GC, Chen HT, Yang TY, Kuo BIT, Hsu HC, et al. Surgical results of metastatic spinal cord compression secondary to non-small cell lung cancer. Spine. 2007;32:E413-8.

8. Weiss RJ, Wedin R. Surgery for skeletal metastases in lung cancer. Acta Orthop. 2011;82:96-101.

9. Tokuhashi Y, Matsuzaki H, Toriyama S, Kawano H, Ohsaka S. Scoring system for the preoperative evaluation of metastatic spine tumor prognosis. Spine. 1990;15:1110-3.

10. Tokuhashi Y, Matsuzaki H, Oda H, Oshima M, Ryu J. A revised scoring system for preoperative evaluation of metastatic spine tumor prognosis. Spine. 2005;30:2186-91.

11. Tomita K, Kawahara N, Kobayashi T, Yoshida A, Murakami H, Akamaru T. Surgical strategy for spinal metastases. Spine. 2001;26:298-306.

12. Van Der Linden YM, Dijkstra SPDS, Vonk EJA, Marijnen CAM, Leer JWH. Prediction of survival in patients with metastases in the spinal column. Results based on a randomized trial of radiotherapy. Cancer. 2005;103:320-8. 
13. Sioutos PJ, Arbit E, Meshulam CF, Galicich JH. Spinal metastases from solid tumors. Analysis of factors affecting survival. Cancer. 1995;76:1453-9.

14. Bauer HC, Wedin R. Survival after surgery for spinal and extremity metastases. Prognostication in 241 patients. Acta Orthop Scand. 1995;66:143-6.

15. Bartels RH, Feuth T, Van Der Maazen R, Verbeek AL, Kappelle AC, Grotenhuis $J A$, et al. Development of a model with which to predict the life expectancy of patients with spinal epidural metastasis. Cancer. 2007;110:2042-9.

16. Hessler C, Vettorazzi E, Madert J, Bokemeyer C, Panse J. Actual and predicted survival time of patients with spinal metastases of lung cancer: evaluation of the robustness of the Tokuhashi score. Spine. 2011;36:983-9.

17. Morgen SS, Lund-Andersen C, Larsen CF, Engelholm SA, Dahl B. Prognosis in patients with symptomatic metastatic spinal cord compression: survival in different cancer diagnosis in a cohort of 2321 patients. Spine. 2013;38:1362-7.

18. Carr LL, Finigan JH, Kern JA. Evaluation and treatment of patients with non-small cell lung cancer. Med Clin North Am. 2011;95:1041-54.

19. Cagle PT, Chirieac LR. Advances in treatment of lung cancer with targeted therapy. Arch Path Lab Med. 2012;136:504-9.

20. Frankel HL, Hancock DO, Hyslop G, Melzak J, Michaelis LS, Ungar GH, et al. The value of postural reduction in the initial management of closed injuries of the spine with paraplegia and tetraplegia. Paraplegia. 1969;7:179-92.

21. Heary RF, Bono CM. Metastatic spinal tumors. Neurosurg Focus. 2001;11:e1.

22. Walker MP, Yaszemski MJ, Kim CW, Talac R, Currier BL. Metastatic disease of the spine: evaluation and treatment. Clin Orthop Relat Res. 2003;415:S165-75.

23. Crnalic S, Löfvenberg R, Bergh A, Widmark A, Hildingsson C. Predicting survival for surgery of metastatic spinal cord compression in prostate cancer: a new score. Spine. 2012;37:2168-76.

24. Yamashita $T$, Siemionow KB, Mroz TE, Podichetty V, Lieberman $\mathbb{I H}$. A prospective analysis of prognostic factors in patients with spinal metastases: use of the revised Tokuhashi score. Spine. 2011;36:910-7.

25. Quraishi NA, Manoharan SR, Arealis G, Khurana A, Elsayed S, Edwards KL, et al. Accuracy of the revised Tokuhashi score in predicting survival in patients with Metastatic Spinal Cord Compression (MSCC). Eur Spine J. 2013;22:S216.

26. Rades D, Douglas S, Veninga T, Schild SE. A validated survival score for patients with metastatic spinal cord compression from non-small cell lung cancer. BMC Cancer. 2012;12:302.

27. Moon KY, Chung CK, Jahng TA, Kim HJ, Kim CH. Postoperative survival and ambulatory outcome in metastatic spinal tumors : prognostic factor analysis.J Korean Neurosurg Soc. 2011;50:216-23.

28. Bach F, Agerlin N, Sorensen JB, Rasmussen TB, Dombernowsky P, Sorensen PS, et al. Metastatic spinal cord compression secondary to lung cancer. J Clin Oncol. 1992;10:1781-7.

\section{Submit your next manuscript to BioMed Central and take full advantage of:}

- Convenient online submission

- Thorough peer review

- No space constraints or color figure charges

- Immediate publication on acceptance

- Inclusion in PubMed, CAS, Scopus and Google Scholar

- Research which is freely available for redistribution 